\title{
Limitations of Remote Laboratories in Control Engineering Education
}

\author{
doi:10.3991/ijoe.v6i1.1131 \\ Nourdine Aliane $^{1}$, Rafael Pastor ${ }^{2}$ and Gonzalo Mariscal ${ }^{1}$ \\ ${ }^{1}$ Universidad Europea de Madrid, Madrid (Spain) \\ ${ }^{2}$ Universidad Nacional de Educación a Distancia (Spain)
}

\begin{abstract}
Remote laboratories have made significant progress during last few years. Their integration in engineering education helps solve many logistical difficulties inherent in conventional labs. In control engineering education, shifting from hands-on experience to remote experimentation completely modifies the learning environment. Also, factors that can compromise the effectiveness of learning outcomes need to be carefully considered. This short paper discusses a number of pedagogical limitations intrinsic to remote experimentation in control engineering education.
\end{abstract}

Index Terms-Remote Laboratories, Control Engineering Education, Pedagogical Issues.

\section{INTRODUCTION}

Internet-based technology is rapidly being adopted in engineering education as a tool for enhancing the educational experience, thus enabling access to remote labs to perform real experiments. Remote labs are real equipment that can be operated remotely through an online interface [1]. Their use is generalized to all the engineering areas [2]. The technological development of remote laboratories has made significant progress during recent years, as witnessed by the numerous projects investigating remote access to laboratories used in science and engineering education which are funded by the European Union, where the most representative were CYBERLAB [3], PEARL [4] and MARVEL [5], among others. Remote experimentation has also een the subject of many publications during last few years. In a comparative literature survey of handon and remote laboratories [2], a search in three electronics databases (IEEE, ACM, and ScienceDirect) was carried out and over 1000 papers were found, the majority of which principally addressed technical aspects.

In the area of control engineering, the idea of accessing laboratory equipment using the Internet for educational purposes is not new. In the nineties, [6] proposed a remotely shared control system laboratory which enabled sharing of laboratory data between universities and the earliest implementation of a remote control lab to education had been reported in [7]. Since then, remote control labs have been an important topic of research. In this context, it is worth mentioning the work [8-9] at Siena University [10-12], the Stevens Institute of Technology and [13-15] the Spanish Open University. As a result of these efforts, a wide variety of remote lab systems have been developed by educational institutions around the word. A representative list of remote control labs is given in the Appendix. All these platforms offer users control over a number of classical models, such as level control, temperature control, or position/velocity control.

Remote labs have had based their justification on the logistical problems. Indeed, they can make available a wide range of lab resources and can provide more efficient sharing of unique or expensive equipment, as well as simplify equipment scheduling or lab space. Students can use the remote lab at any time and at any place to realize more experiments. However, the decision whether to shift to remote experimentation or not is not simply a matter of developing a remote lab platform using this or that technology and justify its use by solving logistical problems related to conventional labs. It is also important to examine whether the use of remote experimentation helps meet learning outcomes or not.

There is no doubt that hands-on experience plays an important role in control education. In his plenary lecture [16], Astrom claimed that it is essential to have hands on experience in order to have good engineering appreciation of control. The role of the laboratory in engineering education is analyzed from many aspects in [17], where the author states that there is a lack of consensus on the basic objectives of the laboratory experience, and that it is not clear what students are expected to accomplish. They also claim that the absence of a set of fundamental objectives for laboratories has limited educators assessing the effectiveness of laboratory experiences. This is also true for remote labs. In [2], the author raises the question about the effectiveness of remote labs, to which they do not provide a response. In this blurred context, however, our short experience in using remote labs has shown us several limitations intrinsic to remote experimentation in control education [14], [18].

\section{Pedagogical Limitations of Remote LAB IN CONTROL EDUCATION}

Control engineering is a systems field that constitutes a good arena for laboratory practices [16]. In control lab activities, students must handle elements such as sensors, actuators, processes, computers, and specific software package. On one hand, it is essential to ensure that students correctly operate laboratory instruments, such as oscilloscopes, functions generators, power supplies, or digital multi-meters, to acquire the necessary skills to perform tasks ranging from calibrating transducers to fall diagnosis. On the other hand, control lab activities use more specific software packages such as Matlab/Simulink or LabView in tasks including acquiring data, analyzing results, performing simulations, or controlling systems. Consequently, correctly operating lab instrumentation 
constitutes a added value for control engineering students. It important to stress that the majority of current remote control engineering labs focus only on control experiments, and obviously do not offer the possibility of handling laboratory instruments, which naturally constitutes a serious deficiency. In this aspect, conventional laboratories may indeed represent the only feasible manner by which students can learn to correctly operate laboratory instruments.

Process control of experiments oriented to study the effects of load disturbances are challenging. Indeed, many laboratory pilot-scale models offer the possibility of carrying out control experiments aimed at evaluating control strategies (or controller tuning) not only with respect to reference inputs, but also to load disturbances. In many industrial control problems, the responses to load disturbances are much more relevant than the responses to input references. However, many laboratory pilot-scale models only admit the manual introduction of disturbances. For example, this is the case for the models used in our remote laboratory [18]: the temperature model is disturbed by manually opening the window or setting the external temperature, or the level model is disturbed by manually changing the outflow. This characteristic, which is present in many commercial models, makes it difficult for remote control engineering labs to offer experiments with disturbances. In fact, none of the remote control labs listed in the appendix offer this possibility, and all these remote labs are based on providing simple open or closed control experiments with respect to reference inputs. Exclusively using remote labs will, therefore, not be possible because of an important lack of disturbances on control system behavior. However, these kinds of experiments might be feasible if laboratory models come with electrical mechanisms for generating disturbances.

It is also important to notice that the majority of current remote labs focus only on simple feedback by controlling systems using PID controllers, and they do not offer experiments with other control strategies, such as cascade control, feed-forward compensation or state feedback, just to name a few examples. The same criticism can be made about filtering measurement noise and none of the remote labs listed in the appendix offer the possibility of studying the effect of such issues.

Besides acquiring specific knowledge and skills, it is known that hands-on experiences increase student motivation and helps create a learning environment that permits students to develop general competencies, where they can learn to work in teams, meet deadlines and work schedules, communicate effectively, manage conflicts, as well as many others skills that are applicable across a broad range of engineering professions. Traditionally, these skills were not taken into account as a primary educational goal, but they are constantly worked on through actual hands-on experience. In the same way, conventional labs constitute an authentic arena for collaborative learning, in which students are engaged and interact with their peers as they work in groups in order to gain greater understanding or discover solutions to a myriad of problems. Today, collaborative learning environments focus mainly on theoretical lessons, and this feature is very limited or not supported by current remote labs [19]. Thus, replacing conventional hands-on labs with remote lab activities does not guaranty the development of aforementioned general competencies or collaborative learning competencies with the same level of effectiveness. Thus, basing hands-on experience exclusively on remote experimentation will entail partially renouncing the inherent advantages of conventional labs.

From a pedagogical point of view, laboratory activities should provide adequate practical assignments according to the educational objectives, and should be established independent of the lab type (real or remote lab). Bearing in mind the aforementioned limitations, remote control labs are clearly insufficient to ensure effective hands-on experiences, and their integration in control education could significantly affect students' learning outcomes. However, remote experimentation could be used to complement the traditional lab activities by providing more flexibility to traditional labs. This approach, referred to as "mixed lab", is currently used in several institutions [10], [19], where the essential laboratory learning experience is still facilitated by real hands-on activities that emphasize lab activities to develop skills, while more specific key concepts can be complemented using remote experimentation. The combination of in-situ and remote experimentations can define more flexible ways to carry out lab activities. For example, students might begin lab activities insitu, and then conclude their work by remote access to the lab.

\section{CONCLUSIONS}

In this short paper, some limitations of remote labs intrinsic to control engineering education have been addressed. First, remote environments do not offer students the possibility of correctly operating laboratory instruments, or learning to use more specific software packages, such as Matlab/Simulink or LabView. Second, many remote labs do not offer the option of carrying out experiments oriented to studying the effects of disturbances, and few remote labs allow experimentation with other control strategies, such as cascade control, feed-forward compensation, or state feedback. Finally, carrying out lab activities exclusively using remote labs cannot provide the same learning environment in traditional labs in terms of developing general competencies and collaborative learning, and do not ensure learning outcomes at the same level of effectiveness at which they are achieved in conventional labs.

Remote labs are clearly insufficient in providing adequate practical assignments that meet educational objectives, and their integration in control engineering education should be cautiously considered. The rational use of remote labs ultimately depends on the understanding of the pedagogical issues justifying their use. However, remote control engineering labs can be used in conjunction with conventional hands-on labs, where the essential laboratory learning experience is still facilitated by real handson experiences that emphasize design skills, while more specific key concepts can be complemented using remote experimentation.

\section{APPENDIX}

Some remote labs for control education. This list should be regarded as representative, not a ranking. All the URLs were active as of September 2009.

1. ACT, Telelab: http://www.dii.unisi.it/ control/act/home.php 
2. Cyberlab: http://www.cyberlab.org/frames_cl.php

3. DIA, UNED-Spain: http://lab.dia.uned.es/rlab/index.html

4. eMersion, École Polytechnique Fed. de Lausane: http://lawww.epfl.ch/page13172.html

5. MPCRL, Polytechnic University at NY: http://mechatronics.poly.edu/MPCRL/

6. NUS, National University of Singapore: http://vlab.ee.nus.edu.sg/vlab/

7. Stevens Institute of Technology: http://dynamics.soe.stevens-tech.edu/

8. University of Tennesee at Chatanooga: http://chem.engr.utc.edu/Webres/Stations/controlslab.html

\section{ACKNOWLEDGMENT}

This work was supported by the Spanish "Plan Nacional I+D+I del Ministerio de Ciencia e Innovación” under Grant TIN2008-06083-C03/TSI.

\section{REFERENCES}

[1] S. Dormido, "Control learning: present and future". Annual Reviews in Control, vol. 2, no 1, 2004, pp. 115-136.

[2] J. Ma, and J. Nickerson, "Hands-on, simulated, and remote laboratories: A comparative literature review". ACM Computing Surveys, vol. 38, no3, 2006, article 7.

[3] CYBERLAB: http://www.cyberlab.org/new/index.php

[4] PEARL: $\underline{\text { http://iet.open.ac.uk/pearl/index.htm }}$

[5] MARVEL: http://www.marvel.uni-bremen.de

[6] M. F. Aburdene, E. J. Mastascusa and R. Massengale, “A proposal for a remotely shared control systems laboratory", In Proc. of the ASEE, Frontiers in Education Conference, pp. 589-592, 1991.

[7] B. Aktan, and C.A. Bohus, "Distance Learning Applied to Control Engineering Laboratories", IEEE Trans. on Education, vol 39, no.3, 1996, pp. 320-326. (doi:10.1109/13.538754)

[8] M. Casini and D. Prattichizzo, "The automatic control Telelab: A user-friendly interface for distance learning", IEEE Trans. on Education, vol. 46, no. 2, 2003, pp.252-257. (doi:10.1109/TE.2 002.808224)

[9] M. Casini, M., D. Prattichizzo and A. Vicino, "The automatic control Telelab: A Web-based technology for distance learning", IEEE Control Systems Magazine, vol. 24, no. 3, 2004, pp.36-44. (doi:10.1109/MCS.2004.1299531)

[10] S. K. Esche, "On the integration of remote experimentation into undergraduate laboratories: Technical implementation”, International Journal of Instructional Media, vol. 33, no. 1, 2006, pp. 4353.

[11] J.V. Nickerson, J. E. Corter, and S. K Esche, "A model for evaluating the effectiveness of remote engineering laboratories and simulations in education”, Computers and Education, vol 49, no. 3, 2007, pp. 708-725. (doi:10.1016/j.compedu.2005.11.019)
[12] E. S. Aziz, S. K. Esche, and C. Chassapis, "Content-Rich Interactive Online Laboratory Systems", Computer Application in Engineering Education, Published Online in Wiley-InterScience DOI 10.1002/cae.20210. 2009.

[13] J. Sánchez, S. Dormido, P. Pastor, and F. Morilla, “A JAVA/MATLAB-based environment for remote control systems laboratories: Illustrated with an inverted pendulum”, IEEE Trans. on Education, vol. 43. no. 3, 2004, pp. 321-329. (doi:10.1109/ TE.2004.825525)

[14] R. Pastor, C. Martín, J. Sánchez and S. Dormido, “Development of an XML-based lab for remote control experiments on a servo motor”, International Journal of Electrical Engineering Education, vol. 42, no.2, 2005, pp. 173-184.

[15] R. Dormido, H. Vargas, N. Duro, S. Sanchez, S. Dormido, G. Farias, et $a l$, "Development of a web-based control laboratory for automation technicians: The three-tank system", IEEE Trans. on Education, vol. 51, no. 1, 2008, pp35-44. (doi:10.1109/TE.2007. $\underline{893356)}$

[16] K. J. Astrom, "Challenges in control education", In Proc. of the 7th IFAC Symposium on Advances in Control EducationACE’06, Madrid-Spain pp. 9-29, 2006.

[17] F. D. Lyle, and R. J. Albert, "Role of the laboratory in undergraduate engineering education", Journal of Engineering Education, vol. 94, no. 1, 2005, pp. 121-131.

[18] N. Aliane, A. Martínez, A. Fraile and J. Ortiz. "LABNET: A remote control engineering laboratory", International Journal of Online Engineering vol. 3, no.2, 2007, [OnLine], http://www.ijoe.org/ojs/viewarticle.php?id=97. Retrieved, 15 March 2009.

[19] C. A. Jara, F. Candelas, F. Torres, S. Dormido, F. Esquembre and O. Reinoso, "Real-time collaboration of virtual laboratories through the Internet", Computers and Education, vol. 52, no.1, 2009, pp.126-140. (doi:10.1016/j.compedu.2008.07.007)

[20] D. Gillet, A. V. Nguyen and Y. Rekik, "Collaborative Web-based experimentation in flexible engineering education”, IEEE Trans. on Education, vol. 48, no. 4, 2005, pp. 696-704. (doi:10.1109/TE. $\underline{\text { 2005.852592) }}$

\section{AUTHORS}

Nourdine Aliane is with the Computer Architecture and Automation Department (DACA) at the Universidad Europea de Madrid -Villaviciosa de Odón, 28670, Madrid, Spain, (e-mail: nourdine.aliane@uem.es)

Rafael Pastor is with the Computer Science \& Automation Department at the UEND-Avenida del Rey, no 9, 28040, Madrid, Spain, (e-mail: rpastor@scc.uned.es)

Gonzalo Mariscal is with the Computer Architecture and Automation Department (DACA) at the Universidad Europea de Madrid -Villaviciosa de Odón, 28670, Madrid, Spain, (e-mail: gonzalo.mariscal@uem.es)

Manuscript received 1 November 2009. Published as resubmitted by the authors 20 January 2010. 